\section{Digital Divide and Robotics Divide}

Éva Berde

Department of Microeconomics, Corvinus

University of Budapest, Budapest, Hungary

Demography and Economics Research Centre,

School of Economics, Corvinus University of

Budapest, Budapest, Hungary

\section{Synonyms}

Digital segregation; Gaps in Internet access; Inequalities in Internet access; Robotization and the digital divide

\section{Definitions}

Digital divide denotes the social and economic inequality caused by the differences in the usage of information and communication technologies (ICTs), which are, basically, a consequence of different quantities and qualities of Internet consumption. It was first mentioned in a report by the National Telecommunications and Information Administration (McConnaughey et al. 1998), in which "digital divide" was meant to illustrate the US citizens' and companies' differences in Internet access. Since then, the digital divide has been used to describe differences between countries, regions, and continents and to compare groups by age, gender, socioeconomic status, ethnicity, and geography.

\section{Overview}

In the twenty-first century, the growing importance of robotics heavily relies on ICTs, especially its branch requiring Internet usage. Thus, robotics divide can be regarded as a natural consequence of the digital divide. Measuring the influence of robotization on society and individuals, "robotics divide" points out the differences in power, information, and living and predicts potential future gaps. Robotics divide also shows the way technology and the availability thereof redefine the power structure of a society. It strongly emphasizes the military applications of robotization and their influence on power. The robotization of various fields, especially the development of online bots, is of strategic importance for individual countries, and they play a crucial role in the twenty-first-century race for hegemony. Rivalry for the top positions is especially fierce among the United States, China, India, and Russia (López-Peláez 2014). However, the digital divide is not only crucial from a governmental strategic point of view, but it also counts for individuals, as shown by Green and Rossall (2013). People not using the Internet and tools based on the Internet will become disadvantaged compared to their peers. It is especially true for the older generation, who often have physical and health restrictions 
as well and would tremendously benefit from accessing services and companionship across the Internet.

\section{The Specific Phases of the Digital Divide}

The digital divide in the late twentieth century was mainly determined by the number of people and the proportion of companies that had Internet access. In December 1995, a mere $0.4 \%$ of the global population had access to the Internet. By December 2017, the rate was $54.4 \%$. This rise, however, does not reveal the vast inequalities between continents. Currently, 95\% and $85.2 \%$ of the North American and European population have direct Internet access, respectively, while this rate is only $36.2 \%$ in Africa (Internet World Stats 2019).

Internet access can be made via a growing number of devices; the role of smartphones is especially marked in developing countries. Due to the rapid spread of smartphones, the development of Internet penetration is expected to speed up even in underdeveloped regions. The simple digital divide gave way to the second- and thirdlevel digital divide, both gaining importance. Second-level digital divide refers to the differences between the skills needed to use the Internet effectively, whereas third-level divide refers to the differing real advantages generated by efficient Internet usage (Scheerder et al. 2017). One example of a third-level digital divide is the contribution of online accessibility to economic development. In some countries, the application of online technologies contributes to economic development, while in others, it does not or at least not to the same level. In the latter countries, even if Internet access is provided to citizens, online methods cannot penetrate the economic bloodstream in each social group. Offline inequalities are usually inherited into the online world. This way, the third-level digital divide is intricately linked to the robotics divide.

\section{The Expected Divide Related to the Automation and Robotization}

Robotization already plays essential roles in production and consumption alike, and its importance is expected to grow rapidly throughout the future decades of the twenty-first century. Countries that introduce robots to an increasing number of economic sectors can expect swift economic development, stronger military power, and more technological innovations, and they will also be able to defend their borders more easily than countries that are slower to embrace robotization. The robotization of companies will result in higher productivity rates, and companies reluctant to introduce robots will experience a fall in competitiveness. The lives of people living or working together with robots will become more comfortable since they can delegate household chores and have more leisure time. They can even study more effectively and get jobs more efficiently than their peers who live in a "robotfree” environment (López-Peláez 2014).

To study the personal use of robotics among the population, we must go back to Internet usage as this is the tool providing access to robotics for individuals. The ratio of Internet users in the United States and Europe is especially high. However, older people are still left behind. A survey in the United Kingdom - a country with high Internet usage - has shown that Internet use is not prevalent among the oldest people (Davidson 2018). Only $44 \%$ of those aged 75 years and over used the Internet regularly in 2018 despite some of them having been online previously. Internet use would be especially crucial for this generation to access health-related, communication, and information tools easily. People staying away from the Internet will not benefit from the rapidly developing household robotization either.

\section{The Effects of the Digital Divide and Robotics Divide on the Life of the Older Generation}

Both the digital divide and robotics divide are in close correlation with various demographic indicators. Age, for instance, demonstrates a difference between people aged 25-54 and 55+, with the latter group still lagging in Internet usage (See > "Aging in the Digital Age"). According to data by Eurostat (2018), the difference was almost 30 percentage points in the European Union (EU). This difference is leveling out rapidly and not only for the sole reason that today's youth is tomorrow's older generation. Especially in developed 
countries, the older generation who had had no access to the Internet earlier has become aware of Internet users. This process is enhanced by organized education strategies, for example, the Universities of the Third Age (Klimczuk 2013). If the education is regarded as resulting in online consumption and work as a constituent of the silver economy, it is safe to say that such training can contribute to economic development (Klimczuk 2017). One of the essential tasks in this field is to mitigate the second-level digital divide and thirdlevel digital divide differences within the older generation.

With regard to older people's way of life, the Internet divide may cause severe differences in living standards (See $>$ "Investment in the Longevity Economy"). The so-called narrow Internet users are employing the Internet for a maximum of 2-3 simple tasks and are unable to operate household robotics (Centre for Ageing Better 2018). Those on the other hand which may have access to healthcare robots, household robots, and robots facilitating everyday routine can have a much more comfortable and secure life, and also they may live longer than their peers excluded from robotized services (López-Peláez 2014).

Robotic methodologies utilized in the household of the older people can be divided into two groups (Jutai and Southall 2013): medical technologies and assistive technologies. Medical technologies intervene by healing certain disorders and improving physical health. Medical robots can provide treatments to older people in their own homes. Formerly, such treatments were only available in institutions specializing in older people's care (Yusif et al. 2016). Various motion sensors and monitoring instruments attached to the body will trigger immediate emergency calls - their efficiency can even surpass that of qualified care professionals. Nowadays, older people can spend their days at their homes, with relatives, and in familiar surroundings, leading more or less the same way of life they used to lead. The acceptance of healthcare robots still has to overcome many obstacles; however, as the general acceptance of robots increases, such difficulties will soon be eliminated. There is one blot: since it is only the wealthy members of society that can afford healthcare robots, the robotics divide will increase without estimated community financing.

Assistive technologies, which are used to increase living standards, form the other group of robotics regularly employed by older people (Jutai and Southall 2013). People utilizing assistive technologies also suffer from some level of health difficulties. Nevertheless, their lives would not be in danger without these technologies. Their standard of living would improve; however, with the use of assistive technology, they might even be on the same level as healthy people (See - "Home Health Technologies").

The third category of robots includes those household robots providing convenience services for both older and younger people. Access to these robots is still crucially important for older people (See $>$ "Aging in Place: Maintaining Quality of Life for Older Persons at Home"); as for them, simple household tasks are even harder and require more energy (Jutai and Southall 2013). Living in a smart house can be especially lucrative where almost all everyday household tasks are carried out by robots.

Robotization can also help older laborers in the workplace. Tedious laboring work, monotonous, and boring tasks will be primarily done by robots in the future. According to Thomas et al. (2016), this is, on the one hand, a challenge and, on the other hand, an opportunity for older people. Thus, it will also become possible for the older generation to stay longer in the labor market and do a job that is useful to themselves and society. This age management and labor market policies need a proper investigation of what older people can do (See "Age Management and Labor Market Policies"). Also, to be able to work longer, gray hairs will have to learn how to cooperate with robots. The idea of the Universities of the Third Age mentioned above (Klimczuk 2013) may greatly facilitate this process (See "Senior Learning"). There might be older individuals struggling to acquire even the basis of Internet use; they can benefit from personalized support showcase by the Centre for Ageing Better (2018). 
How the Governments Can Mitigate the Risks Associated with the Digital Divide and Robotics Divide

If governments are not careful enough, the gap between the rich and the poor will be further widened by technological innovations, artificial intelligence, and robotization (See $>$ "Aging Policy Ideas"). Older people who are unable to change their way of life are all the more exposed to its effects. For this reason, it is crucial that governments pay attention to those leaving the labor market permanently and use public money to mitigate the inequalities arising between the younger and the older generations (Baker 2001). The role of governments needs to be emphasized with regard to older people for whom home robotics may cease the need for hospital admission and could lead to significant healthcare savings. These medical robotics devices can rarely be afforded individually, and their use requires regular professional supervision involving high costs. Nevertheless, in some instances, for example, for those who have dementia, the use of robotics is still cost-effective compared to inpatient hospital stays (See $>$ "Cost-effectiveness of Aging Therapies”) (Mountain 2013).

\section{Future Directions of Research}

Although more and more studies analyze the digital divide, only a few of these examine the digital divide among the older people as this will be a task for the future. Cost-benefit analysis of the newest robotic technologies and the review of relatively widespread methodologies are also essential. One of the most important causes of the digital divide among older people is the lack of wealth. Researchers have to examine how can governments contribute to the decrease of the digital divide between poor and rich in older age.

\section{Summary}

The rapid increase in Internet usage does not necessarily mean that Internet use among the older generation is also widespread. Although the extensive consumption of smartphones massively increased Internet usage in less-developed countries as well, the use of the Internet among the older population still lags. While the first degree of the digital divide using the Internet for simple tasks decreased significantly in the last 10 years, the second- and third-degree divide is still substantial between different generations. The older generation only rarely uses the Internet for more complicated tasks such as banking, group communication, or remote working. The gray hairs are also more reserved regarding the use of robotics based on the Internet, such as robots doing labor or robots for convenience. In summary, although the first degree of the digital divide is reducing, the second and third levels are still substantial.

\section{Cross-References}

\section{- Age Management and Labor Market Policies}

- Aging Policy Ideas

- Digital Health

D Domestic Robot

- Home Health Technologies

- Investment in the Longevity Economy

- Senior Learning/Lifelong Learning

- Smart Homes

University of the Third Age

\section{References}

Baker PM (2001) Policy bridges for the digital divide: assessing the landscape and gauging the dimensions. First Monday 6(5). https://doi.org/10.5210/fm.v6i5.860

Centre for Ageing Better (2018) The digital age: new approaches to supporting people in later life get online. Centre for Ageing Better, London. https://www.ageingbetter.org.uk/publications/digital-age. Accessed 1 June 2019

Davidson S (2018) Digital inclusion evidence review 2018. Age UK, London. https://www.ageuk.org.uk/ globalassets/age-uk/documents/reports-and-publicatio ns/age_uk_digital_inclusion_evidence_review_2018. pdf. Accessed 2 June 2019

Eurostat (2018) Digital economy and society statistics households and individuals - statistics. https://ec. europa.eu/eurostat/statistics-explained/index.php/Digi tal_economy_and_society_statistics__households_ and_individuals. Āceessed 2 June $201 \overline{9}$ 
Green M, Rossall P (2013) Age UK digital inclusion evidence report. Age UK, London. https://www.ageuk. org.uk/globalassets/age-uk/documents/reports-and-pu blications/reports-and-briefings/active-communities/rb _sept13_age_uk_digital_inclusion_evidence_review. pdf. Accessed 1 June 2019

Internet World Stats (2019) Internet world stats - usage and population statistics. https://www.internetworldstats. com/. Accessed 1 June 2019

Jutai J, Southall K (2013) Measuring the effectiveness of assistive technology on active aging: capturing the perspectives of users. In: Sixsmith A, Gutman G (eds) Technologies for active aging. Springer, Boston, pp 95-103. https://doi.org/10.1007/978-1-4419-8348-0_6

Klimczuk A (2013) Universities of the Third Age in Poland: emerging model for 21 st century. J Educ Psychol Soc Sci 1(2):8-14

Klimczuk A (2017) Sociological and gerontological perspectives on ageing, creativity, and the Third Age. In: Klimczuk A (ed) Economic foundations for creative ageing policy, volume II: putting theory into practice. Palgrave Macmillan, New York, pp 35-54. https://doi. org/10.1057/978-1-137-53523-8_3

López-Peláez A (2014) From the digital divide to the robotics divide? Reflections on technology, power, and social change. In: López-Peláez A (ed) The robotics divide: a new frontier in the 21 st century? Springer,
London, pp 5-24. https://doi.org/10.1007/978-1-44715358-0 2

McConnaughey J, Lader W, Chin R (1998) Falling through the net II: new data on the digital divide. National Telecommunications and Information Administration. Department of Commerce, US Government, Washington, DC

Mountain G (2013) Using technology to support people with dementia. In: Sixsmith A, Gutman G (eds) Technologies for active aging. Springer, Boston, pp 105-121. https://doi.org/10.1007/978-1-4419-8348$0+7$

Scheerder A, van Deursen A, van Dijk J (2017) Determinants of Internet skills, uses and outcomes. A systematic review of the second-and third-level digital divide. Telematics Inform 34(8):1607-1624. https:// doi.org/10.1016/j.tele.2017.07.007

Thomas C, Stankiewicz L, Grötsch A, Wischniewski S, Deuse J, Kuhlenkötter B (2016) Intuitive work assistance by reciprocal human-robot interaction in the subject area of direct human-robot collaboration. Procedia CIRP 44:275-280. https://doi.org/10.1016/j.procir.201 6.02 .098

Yusif S, Soar J, Hafeez-Baig A (2016) Older people, assistive technologies, and the barriers to adoption: a systematic review. Int J Med Inform 94:112-116. https://doi.org/10.1016/j.ijmedinf.2016.07.004 